\title{
Doppler and 3D ultrasound in prediction of the nature of adnexal swelling
}

\author{
Yahia A. Wafa ${ }^{(1)}$, Ismail M. Al-Garhy ${ }^{(1)}$, Prof. Dr. Nabeil M. Fekry ${ }^{(2)}$, \\ Ahmed S. Abdelhamid
}

(1) Department of Obstetrics and Gynecology, (2) Al-Agouza Police Hospital

Corresponding author: Ahmed S. Abdelhamid; Mobile: 01100002523; Email: dr.ahmedsabryallam@icloud.com

\begin{abstract}
Background: An adnexal mass (mass of the ovary, fallopian tube, or surrounding connective tissues) is a common gynecologic problem. Early diagnosis and intervention is essential especially in younger women to conserve the ovarian function. Aim of the Work: to evaluate the usefulness and value of Doppler and 3D Ultrasound as a method to enhance differentiation between benign and malignant pathologies before surgical intervention in women having adnexal swellings. Patients and Methods: This study was carried out in Obstetric and Gynecology Departments in Al-Azhar University Hospitals on 30 patients who had a preliminary diagnosis of an adnexal mass. After history taking and clinical examination, all patients underwent abdominal sonographically, Doppler examination and 3D ultrasound scan from April 2017 to September 2018. Results: Women with malignant masses were older than those with benign masses (46.00 \pm 9.76 vs $44.50 \pm 7.62$ years) respectively. BMI in benign cases was lower than recorded in malignant cases $(30.13 \pm 3.21$ vs $38.57 \pm 0.81)$ with statistical significant difference between two them $(\mathrm{P}<0.01)$. Malignant cases were higher in postmenopausal 4(67\%) while Benign masses were higher in premenopausal 19 (79.2\%) while, five cases (83\%) of malignant cases were nulliparous. Regarding the diagnostic accuracy for the prediction of adnexal malignancy with 3DPD histogram analysis have been satisfied. Resistance index (RI) in benign cases ranged from $0.50-1.90$ with mean value $1.18 \pm 0.41$ and in malignant cases ranged from 0.30-1.50 with mean value 0.77 \pm 0.50 . Sensitivity, specificity, PPV, NPV of RI was 78.8\%, 75.0\%, 77.2\% and $76.1 \%$ respectively. Pulsatility index (PI) in benign cases ranged from 0.61-2.50 with mean value $1.80 \pm 0.52$ and in malignant cases ranged from $0.80-1.37$ with mean value $1.09 \pm 0.24$. Sensitivity, specificity, PPV, NPV of PI was 90.9\%, 88.0\%, 91.0\% and $86.5 \%$ respectively Peak systolic velocity (PSV) in benign cases ranged from 2.00-11.00 with mean value 6.88 \pm 2.71 and in malignant cases ranged from 14.00-35.00 with mean value 22.83 \pm 7.31. Sensitivity, specificity, PPV, NPV of PSV was $100 \%, 100 \%, 100 \%$ and $100 \%$ respectively. There was statistical significant difference between two studied groups regarding to resistance index, pulsatility index and peak systolic velocity $(\mathrm{P}<0.05)$. The high risk was higher in malignant cases with $5(83.3 \%)$ and lower in benign cases $(1 ; 4.2 \%)$. There was statistical significant difference between two studied groups regarding to 3D ultrsound examination $(\mathrm{P}<0.05)$. Conclusion: 3D ultrasound with color Doppler scan characteristics are found to be very important for discriminating benign from malignant tumors. Key words: Doppler, 3D ultrasound, benign/malignant pathologies, nature of adnexal swelling
\end{abstract}

\section{Introduction}

Adnexal swellings or masses represent a spectrum of conditions from gynecological and nongynecologic sources. Gynecological sources include the ovaries, fallopian tubes, ectopic pregnancy, tuboovarian abscess, paratubal or paraovarian cyst, hydrosalpinx and broad ligament leiomyoma ${ }^{(\mathbf{1})}$. Nongynecologic sources of adnexal swellings include appendiceal abscess, appendicitis, bladder diverticulum, nerve sheath tumor, pelvic kidney, peritoneal cyst, and gastrointestinal carcinoma ${ }^{(2)}$.

Adnexal masses are considered a group of the most common diseases in gynecology, ovarian tumors, alone, represent two thirds of these cases. The American Cancer Society estimates that 22,280 new cases of ovarian cancer will be diagnosed in 2016 and 14,240 women will die from the disease.
Although ovarian cancer is the 17 th most common cancer in women, it is the fifth most common cause of cancer death in woman, accounting for $5 \%$ of cancer deaths-more than any other gynecologic cancer $^{(3)}$.

Non neoplastic conditions of the ovary that may present as adnexal masses include the following: pregnancy luteoma, hyperplasia of ovarian stroma, hyperthecosis, massive edema, solitary follicle cysts and corpus luteal cysts, multiple follicle cysts (polycystic ovaries), multiple luteinizing follicle cysts and/or corpora lutea, endometriosis, surface epithelial inclusion cysts (germinal inclusion cysts), simple cysts, inflammatory lesions, and paraovarian cysts ${ }^{(4)}$.

The differential diagnosis of adnexal masses remains a clinical challenge, but an accurate diagnosis is essential for adequate management. 
Ultrasound is considered as the first-line diagnostic imaging tool for this task. In spite of the development of different scoring systems and logistical models, the examiner's subjective impression remains the best method of discriminating between benign and malignant adnexal masses ${ }^{(5)}$.

Doppler examination of a pelvic mass has to be performed when there are masses which are strongly suspected to be malignant. Clearly benign masses don't need such examination. Nevertheless Doppler examination may be very useful in the interpretation of a mass which isn't clearly benign ${ }^{(6)}$.

Three-dimensional (3D) ultrasound is a new imaging technique that has become currently available in gynecologic practice, specifically in gynecologic oncology ${ }^{(7)}$. 3D ultrasound is an easy and noninvasive method for the differential diagnosis of various physiological and pathological conditions of the adenxal masses in the clinical practice of obstetrics and gynecology. The 3D improves spatial orientation and access multiplanar views, especially the coronal (reconstructed) plane, which can provide additional information that can depict lesions not easily diagnosed by two-dimensional (2D) ultrasound imaging ${ }^{(8)}$.

In addition, 3D power-Doppler ultra-sonography allows a 3D reconstruction of the vascular network and also calculating vascular indices based on the total and relative amount of power Doppler information within the volume of interest ${ }^{(9)}$..

\section{Aim of the Work}

The aim of the work was to study the usefulness and value of Doppler and 3D Ultrasound as a method to enhance differentiation between benign and malignant pathologies before surgical intervention in women having adnexal swellings.

\section{Patients and Methods}

\section{A) Patients}

This prospective study carried in Obstetric and Gynecology Departments in Al-Azhar University Hospitals. 30 patients who had a preliminary diagnosis of an adnexal mass, which was detected clinically and confirmed sonographically to be adnexal masses were included regardless the patients' complaint, age or parity, and scheduled for surgical intervention from April 2017 to September 2018.

The study was approved by the Ethical Review Board of Al-Azhar University Hospitals and all women gave written informed consent.

\section{Inclusion criteria}

- Patients aged between 18 and 80 years old.

- Approval of a transvaginal ultrasound scan and informed consent provided.

\section{Exclusion criteria}

- Women who pregnant at the time of diagnosis,
- Women underwent surgery at a different center

- If their management was according to expectant follow-up

B- Methods

All patients subjected for the following:

I Full history taking:

- Detailed personal, present, past, family, obstetric, menstrual and contraceptive history including risk factors for ovarian cancer include age older than 60 years; early menarche; late menopause; nulliparity; infertility; personal history of breast or colon cancer; and family history of breast, colon, or ovarian cancer.

- History of risk factors for ectopic pregnancy (medical history of tubal ligation or other tubal surgery, pelvic inflammatory diseases, or use of an intrauterine device).

II General Examination:

- Vital signs, height and body build and other system examination.

- Cervical, supraclavicular, axillary, and inguinal lymph nodes examination.

- Measurements of body weight and height and subsequently calculation of their BMI (weight in $\mathrm{Kg} /$ height 2 in meter)

\section{Abdominal Examination}

- Inspection, palpation, percussion and auscultation.

- A detailed abdominal examination to assess for ascites, masses, tenderness and hepatosplenomegaly.

\section{Pelvic Examination}

- PV examination, bimanual and speculum examination to assess the size, tenderness, location, consistency, and mobility of the uterus and both adnexa.

- A rectovaginal examination was done to assess reveal tenderness or nodularity of the uterosacral ligaments.

\section{Routine Investigations}

- Liver function tests and serum creatinine.

- Complete blood count (CBC).

- Prothrombin time (PT)

\section{Radiological Investigations}

- Abdominal ultrasound examination was performed in patients with a large or suspicious mass to assess the intra-abdominal spread.

- Doppler examination.

- 3D ultrasound scan performed by staff gynecologists or one expert gynecologist with a special interest in gynecological ultrasound.

Ultrasound assessment included following strategy

- Initially, all masses were evaluated by gray-scale ultrasound according to the pattern-recognition approach and using the International Ovarian Tumor Analysis (IOTA) terms and definitions. Masses 
observed with a typical appearance of a benign cyst, such as endometrioma, mature teratoma, simple/serous cyst, hydrosalpinx, paraovarian cyst, hemorrhagic cyst, mucinous cyst or peritoneal cyst were considered as being at low risk for malignancy and did not undergo further assessment by ultrasound.

- Masses with ascites and/or sonographic signs of carcinomatosis were considered as being at high risk for malignancy and did not undergo further assessment except for transabdominal ultrasound to assess the intra-abdominal spread.

- Masses that did not show ascites and/or signs of intra-abdominal carcinomatosis and could not be classified as certainly benign according to pattern recognition and showed solid components (thick papillary projections, irregular internal wall or solid areas), as well as solid tumors, were considered as being at intermediate risk for malignancy. These intermediate-risk masses underwent second-step analysis and were evaluated by two-dimensional (2D) PDA to determine the location and quantity of color signals (IOTA color score) within the mass and specifically within the solid components. When the mass was considered as high risk

Results

Table (1): Final diagnosis of 30 adnexal masses According to IOTA simple rules

\begin{tabular}{|l|l|l|}
\hline Histology & $\mathbf{N}$ & $\mathbf{\%}$ \\
\hline Benign tumor $(\mathbf{n}=\mathbf{2 4})$ & $\mathbf{2 4}$ & $\mathbf{8 0}$ \\
\hline Endometriotic cyst & 7 & 23.3 \\
\hline Dermoid cyst & 4 & 13.3 \\
\hline Fibroma & 4 & 13.3 \\
\hline Mucinous adenoma & 4 & 13.3 \\
\hline Haemorragic cyst & 3 & 10.0 \\
\hline Serous adenoma & 1 & 3.3 \\
\hline Ovarian abscess sequelae & 1 & 3.3 \\
\hline Malignant tumor (n=6) & $\mathbf{6}$ & $\mathbf{2 0}$ \\
\hline Serous borderline tumor & 2 & 6.7 \\
\hline Serous carcinoma & 2 & 6.7 \\
\hline Endometrioid carcinoma & 1 & 3.3 \\
\hline Metastatic tumor & 1 & 3.3 \\
\hline Total & $\mathbf{3 0}$ & $\mathbf{1 0 0}$ \\
\hline
\end{tabular}

\section{Demographicsdata of patients:}

Table (1) shows comparison between benign and malignant cases regarding demographic data. Age in benign cases ranged from 34-60 with mean value $44.50 \pm 7.62$ and in malignant cases

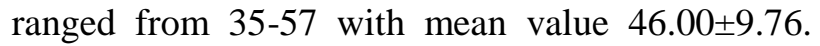
BMI in benign cases ranged from 26.50-36.50 with

Table (2): Comparison between benign and malignant cases regarding demographic data

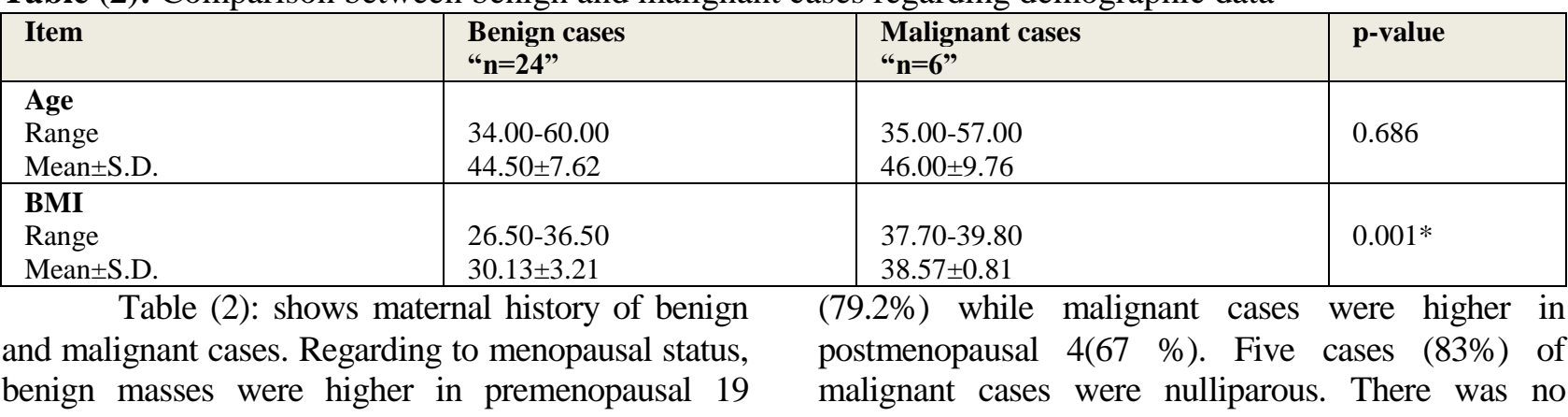


statistical significant difference between two studied

$0.05)$.

groups regarding maternal history and parity $(\mathrm{P}>$

Table (3): Maternal history of benign and malignant cases

\begin{tabular}{|l|l|l|l|l|l|}
\hline \multirow{2}{*}{} & \multicolumn{2}{l|}{$\begin{array}{l}\text { Benign cases } \\
\text { "n=24" }\end{array}$} & \multirow{2}{*}{$\begin{array}{l}\text { Malignant cases } \\
\text { "n=6" }\end{array}$} \\
\cline { 2 - 5 } & No & $\%$ & No. & $\%$ & \\
\hline Menopausal status & & & & & \\
\hline Premenopausal & 19 & 79.2 & 2 & 33.0 & 0.175 \\
\hline Postmenopausal & 5 & 20.8 & 4 & 67.0 & \\
\hline Parity & & & & & \\
\hline Nulliparous & 4 & 16.7 & 5 & 83.0 & 0.388 \\
\hline Parous & 20 & 83.3 & 1 & 17.0 & \\
\hline
\end{tabular}

Table (4) shows family history in the two studied groups. Family history cases in benign group were 14(58.3\%) and in malignant group were $3(33.3 \%)$ while family without history was

Table (4): Family history in the two studied groups

\begin{tabular}{|l|l|l|l|l|l|}
\hline \multirow{2}{*}{ Family history } & \multicolumn{2}{l|}{$\begin{array}{l}\text { Benign cases } \\
\text { "n=24" }\end{array}$} & \multicolumn{2}{l|}{$\begin{array}{l}\text { Malignant cases } \\
\text { "n=6" }\end{array}$} & \multirow{2}{*}{ Palue } \\
\cline { 2 - 5 } & No & $\%$ & No. & $\%$ & \\
\hline No & 10 & 41.7 & 4 & 66.7 & 0.261 \\
\hline Yes & 14 & 58.3 & 2 & 33.3 & \\
\hline
\end{tabular}

Table (5) shows contraceptive history in

relation to histopathological Examination.

$14(58.3 \%)$ and 4(66.7\%) respectively. There was no Contraceptive history cases in benign group were $10(41.7 \%)$ and in malignant group were $2(33.3 \%)$ while cases without contraceptive history were

Table (5): Contraceptive history in relation to histopathological Examination

\begin{tabular}{|l|l|l|l|l|l|}
\hline \multirow{2}{*}{ Contraceptive history } & \multicolumn{2}{l|}{$\begin{array}{l}\text { Benign cases } \\
\text { “n=24” }\end{array}$} & $\begin{array}{l}\text { Malignant cases } \\
\text { “n=6” }\end{array}$ & P value \\
\cline { 2 - 6 } & No & $\%$ & No. & $\%$ & \\
\hline No & 14 & 58.3 & 4 & 66.7 & 0.545 \\
\hline Yes & 10 & 41.7 & 2 & 33.3 & \\
\hline
\end{tabular}

Table (6) shows obstetric, menstrual in relation to Histopathological Examination. Obstetric and menstrual cases in benign group were 13(54.2\%) and in malignant group were $3(50 \%)$ while cases without obstetric, menstrual were $11(45.8 \%)$ and $3(50 \%)$ respectively. There was no statistical significant difference between two studied groups regarding obstetric, menstrual $(\mathrm{P}>0.05)$.

Table (6): menstrual history regularity in relation toHistopathological Examination

\begin{tabular}{|l|l|l|l|l|l|}
\hline \multirow{2}{*}{ menstrual history regularity } & \multicolumn{2}{l|}{$\begin{array}{l}\text { Benign cases } \\
\text { "n=24" }\end{array}$} & \multicolumn{2}{l|}{$\begin{array}{l}\text { Malignant cases } \\
\text { "n=6" }\end{array}$} \\
\cline { 2 - 5 } & No & $\%$ & No. & $\%$ & \\
\hline No & 11 & 45.8 & 3 & 50.0 & \multirow{2}{*}{0.605} \\
\hline Yes & 13 & 54.2 & 3 & 50.0 & \\
\hline
\end{tabular}

Table (7) shows pelvic inflammatory diseases in relation to histopathological examination. Pelvic inflammatory diseases cases in benign group were $12(50 \%)$ and in malignant group were $4(66.7 \%)$ while $12(50 \%)$ and $2(33.3 \%)$ respectively. There was no statistical significant difference between two studied groups regarding pelvic inflammatory diseases $(\mathrm{P}>$ $0.05)$. cases without Pelvic inflammatory diseases were Table (7): Pelvic inflammatory diseases in relation tohistopathological examination

\begin{tabular}{|l|l|l|l|l|l|}
\hline \multirow{2}{*}{} & \multicolumn{2}{l|}{$\begin{array}{l}\text { Benign cases } \\
\text { "n=24" }\end{array}$} & \multirow{2}{*}{$\begin{array}{l}\text { Malignant cases } \\
\text { “n=6" value }\end{array}$} \\
\cline { 2 - 6 } & No & $\%$ & No. & $\%$ & \\
\hline Pelvic inflammatory diseases & & & & & \\
\hline No & 12 & 50.0 & 2 & 33.3 & \multirow{2}{*}{0.395} \\
\hline Yes & 12 & 50.0 & 4 & 66.7 & \\
\hline
\end{tabular}

Table (8) shows distribution of symptoms in the all studied patients group: most patients presented with lower abdominal pain $(12 ; 40 \%)$, abdominal distention $(5 ; 17 \%)$, multiple symtoms $(5 ; 17 \%)$, asymptomatic (4; 13\%) and menstrual disorders (4; $13 \%)$. There was no statistical significant difference between two studied groups regarding presenting symptom $(\mathrm{P}>0.05)$. 
Table (8): Distribution of symptoms in the all studied patients group

\begin{tabular}{|c|c|c|c|c|c|c|}
\hline \multirow[t]{2}{*}{ Presenting symptom } & \multicolumn{2}{|c|}{$\begin{array}{l}\text { Benign cases } \\
\text { "n=24" }\end{array}$} & \multicolumn{2}{|c|}{$\begin{array}{l}\text { Malignant cases } \\
\text { "n=6" }\end{array}$} & \multicolumn{2}{|c|}{$\begin{array}{l}\text { Total } \\
\text { "n=30" }\end{array}$} \\
\hline & No. & $\%$ & No. & $\%$ & No. & $\%$ \\
\hline accidentally discovered & 3 & 12.5 & 1 & 16.7 & 4 & 13.3 \\
\hline Isolated lower abd.pain & 9 & 37.5 & 3 & 50.0 & 12 & 40.0 \\
\hline Abdominal distention & 5 & 20.8 & 0 & 0.0 & 5 & 16.7 \\
\hline Menstrual disorders & 3 & 12.5 & 1 & 16.7 & 4 & 13.3 \\
\hline Multiple symptoms & 4 & 16.7 & 1 & 16.7 & 5 & 16.7 \\
\hline $\mathrm{p}$ & \multicolumn{4}{|c|}{0.816} & & \\
\hline
\end{tabular}

Table (9) shows renal and kidney function in malignant and benign cases. There was no statistical significant difference between two

Table (9): Renal and kidney function in malignant and benign cases

\begin{tabular}{|l|l|l|l|}
\hline Item & $\begin{array}{l}\text { Benign cases } \\
\text { "n=24" }\end{array}$ & $\begin{array}{l}\text { Malignant cases } \\
\text { "n=6" }\end{array}$ & -value \\
\hline $\begin{array}{l}\text { AST } \\
\text { Mean } \pm \text { S.D. }\end{array}$ & $44.83 \pm 10.37$ & $51.17 \pm 14.03$ & 0.222 \\
\hline $\begin{array}{l}\text { ALT } \\
\text { Mean } \pm \text { S.D. }\end{array}$ & $44.50 \pm 11.05$ & $35.67 \pm 9.07$ & 0.082 \\
\hline $\begin{array}{l}\text { Urea } \\
\text { Mean } \pm \text { S.D. }\end{array}$ & $22.67 \pm 5.43$ & $25.33 \pm 5.09$ & 0.286 \\
\hline $\begin{array}{l}\text { Creatinine } \\
\text { Mean } \pm \text { S.D. }\end{array}$ & $0.90 \pm 0.12$ & $1.15 \pm 0.30$ & 0.101 \\
\hline
\end{tabular}

Table (10) shows laboratory findings in malignant and benign cases. There was statistical significant difference between two studied groups Table (10): Laboratory findings in malignant and benign cases

\begin{tabular}{|l|l|l|l|}
\hline Item & $\begin{array}{l}\text { Benigncases } \\
\text { "n=24" }\end{array}$ & $\begin{array}{l}\text { Malignant cases } \\
\text { "n=6" }\end{array}$ & p-value \\
\hline $\begin{array}{l}\text { RBCs } \\
\text { Mean } \pm \text { S.D. }\end{array}$ & $134.92 \pm 33.71$ & $114.83 \pm 41.34$ & 0.222 \\
\hline $\begin{array}{l}\text { Hb } \\
\text { Mean } \pm \text { S.D. }\end{array}$ & $13.22 \pm 0.86$ & $13.00 \pm 0.79$ & 0.580 \\
\hline $\begin{array}{l}\text { HTC } \\
\text { Mean } \pm \text { S.D. }\end{array}$ & $45.20 \pm 2.94$ & $44.46 \pm 2.69$ & 0.580 \\
\hline $\begin{array}{l}\text { WBC } \\
\text { Mean } \pm \text { S.D. }\end{array}$ & $9.72 \pm 1.00$ & $7.10 \pm 1.92$ & $0.05^{*}$ \\
\hline $\begin{array}{l}\text { Prothrombin time } \\
\text { Mean } \pm \text { S.D. }\end{array}$ & $12.20 \pm 1.19$ & $12.55 \pm 1.58$ & 0.551 \\
\hline
\end{tabular}

Table (11) shows resistance index (RI) in relation to pathological findings. RI in benign cases ranged from $0.50-1.90$ with mean value $1.18 \pm 0.41$ and in malignant cases ranged from $0.30-1.50$ with

studied groups regarding renal and kidney function $(\mathrm{P}>0.05)$. regarding WBC $(\mathrm{P}<0.05)$ while, there was no statistical significant difference regarding RBCs, $\mathrm{Hb}, \mathrm{HTC}$ and prothrombin time $(\mathrm{P}>0.05)$

Table (11): Resistance index (RI) in relation to pathological findings

\begin{tabular}{|l|l|l|l|}
\hline RI & $\begin{array}{l}\text { Benigncases } \\
\text { " } \mathrm{n}=24 "\end{array}$ & $\begin{array}{l}\text { Malignant cases } \\
\text { " } \mathrm{n}=6 \text { " }\end{array}$ & $\mathrm{p}$-value \\
\hline Mean \pm S.D. & $1.18 \pm 0.41$ & $0.77 \pm 0.50$ & $0.042^{*}$ \\
\hline
\end{tabular}

Table (12): Sensitivity, specificity, PPV and NPV of RI

\begin{tabular}{|l|l|l|l|l|}
\hline Area & P value & Cut off value & Asymptotic 95\% Confidence Interval \\
\cline { 3 - 5 } & & & Lower Bound & Upper Bound \\
\hline 0.760 & $0.042^{*}$ & 0.60 & 0.499 & 0.95 \\
\hline Sensitivity & 78.8 & \\
Specificity & 75.0 & \\
Positive predictive value & 77.2 & \\
Negative predictive value & 76.1 & \\
\hline
\end{tabular}

Table (13) shows pulsatility index (PI) in relation to pathological findings. PI in benign cases ranged from $0.61-2.50$ with mean value $1.80 \pm 0.52$ and in malignant cases ranged from $0.80-1.37$ with mean value $1.09 \pm 0.24$. There was statistical significant difference between two studied groups regarding to pulsatilityindex $(\mathrm{P}<0.05)$. 
Table (13): Pulsatility index (PI) in relation to pathological findings

\begin{tabular}{|l|l|l|l|}
\hline PI & $\begin{array}{l}\text { Benign cases } \\
\text { "n=24" }\end{array}$ & $\begin{array}{l}\text { Malignant cases } \\
\text { "n=6" }\end{array}$ & p-value \\
\hline & & & \\
Range & $0.61-2.50$ & $0.80-1.37$ & \\
Mean \pm S.D. & $1.80 \pm 0.52$ & $1.09 \pm 0.24$ & $0.003 *$ \\
\hline
\end{tabular}

Table (14): Sensitivity, specificity, PPV and NPV of PI

\begin{tabular}{|l|l|l|l|l|}
\hline Area & P value & Cut off value & \multicolumn{2}{|l|}{ Asymptotic 95\% Confidence Interval } \\
\cline { 3 - 5 } & & & Lower Bound & Upper Bound \\
\hline 0.896 & 0.003 & 1.2 & 0.778 & 0.965 \\
\hline Sensitivity & 90.9 & \\
Specificity & 88.0 & \\
Positive predictive value & 91.0 & 86.5 & \\
Negative predictive value & &
\end{tabular}

Table (15) shows peak systolic velocity (PSV) in relation to pathological findings. PSV in benign cases ranged from 2.00-11.00 with mean value $6.88 \pm 2.71$ and in malignant cases ranged Table (15): PSV in relation to pathological findings

\begin{tabular}{|l|l|l|l|}
\hline PSV & $\begin{array}{l}\text { Benign cases } \\
\text { "n=24" }\end{array}$ & $\begin{array}{l}\text { Malignant cases } \\
\text { "'n=6" }\end{array}$ & p-value \\
\hline Range & $2.00-11.00$ & $14.00-35.00$ & \\
Mean \pm S.D. & $6.88 \pm 2.71$ & $22.83 \pm 7.31$ & 0.000 \\
\hline
\end{tabular}

Table (16): Sensitivity, specificity, PPV and NPV of PSV

\begin{tabular}{|l|l|l|l|l|}
\hline Area & P value & \multirow{2}{*}{ Cut off value } & \multicolumn{2}{|l|}{ Asymptotic 95\% Confidence Interval } \\
\cline { 3 - 4 } & & & Lower Bound & Upper Bound \\
\hline 1.0 & $0.0001^{*}$ & 10.0 & 0.21 & 0.68 \\
\hline Sensitivity & 100.0 & \\
Specificity & 100.0 \\
Positive predictive value & 100.0 \\
Negative predictive value & 100.0 \\
\hline
\end{tabular}

Table (17) shows 3D ultrsound examination in relation to histopathological examination. High risk was higher in malignant cases with $5(83.3 \%)$ There was statistical significant difference between two studied groups regarding to peak systolic velocity $(\mathrm{P}<0.05)$.

while in benign cases it was $1(4.2 \%)$. There was

statistical significant difference between two studied groups regarding to 3D ultrsound examination $(\mathrm{P}<0.01)$.

Table (17): Sensitivity, specificity, PPV and NPV of 3D ultrsound examination in relation to Histopathological Examination

\begin{tabular}{|l|l|l|l|l|l|}
\hline \multirow{2}{*}{ 3D ultrsound examination } & \multicolumn{2}{l|}{$\begin{array}{l}\text { Benigncases } \\
\text { "n=24” }\end{array}$} & \multicolumn{2}{l|}{$\begin{array}{l}\text { Malignant cases } \\
\text { "n=6” }\end{array}$} & \multirow{2}{*}{ P value } \\
\cline { 2 - 6 } & No & 1 & No. & $\%$ & \\
\hline High risk & 5 & 4.2 & 5 & 83.3 & \multirow{2}{*}{$0.0001 *$} \\
\hline Moderate risk & 18 & 20.8 & 1 & 16.7 & \\
\hline Low risk & 18.0 & & \\
\hline Sensitivity & 82.0 & 75.0 & 0 & 0.0 & \\
Specificity & 86.0 & & & \\
Positive predictive value & 84.2 & & & \\
Negative predictive value & 85.0 & & & \\
\hline
\end{tabular}

\section{Discussion}

An adnexal mass (mass of the ovary, fallopian tube, or surrounding connective tissues) is a common gynecologic problem. Early diagnosis and intervention is essential especially in younger women to conserve the ovarian function ${ }^{(10)}$.

Good preoperative discrimination between benign and malignant adnexal massess results in more women with malignancy being correctly referred for gynaecologic oncology care and more women with benign masses undergoing conservative management ${ }^{(11)}$.
Ultrasonography is one of the most evaluated methods for early detection of ovarian cancer. In clinical practice, detected adnexal masses can be classified according to International Tumor ovarian Analysis (IOTA) "simple rules". IOTA simple rules are based on the identification of some simple features during conventional ultrasound examination and presents high sensitivity ${ }^{(12)}$. However, the false positive rate is elevated. About $40-50 \%$ of the women with inconclusive and malignant results by IOTA simple rules have benign ovarian tumors ${ }^{(13)}$. 
Three-dimensional ultrasonography allows quantifying blood flow and vascularization in ovarian tumors. Resistance index, pulsatility index and peak systolic velocity can be calculated after manual outlining of vascularized solid areas within the tumor or after spherical sampling from the most vascularized area of the tumor, the area is selected by the examiner and the spherical sampling performed automatically by the software ${ }^{(14)}$.

In this study, our objective was to evaluate the usefulness and value of Doppler and 3D Ultrasound as a method to enhance differentiation between benign and malignant pathologies before surgical intervention in women having adnexal swellings.

This study was carried in obstetric and Gynecology Departments in Al-Azhar University Hospitals on 3o patients who had a preliminary diagnosis of an adnexal mass, which was detected clinically and confirmed sonographically to be adnexal masses.

By histopathological examination of adnexal masses, there appeared to be $24(80 \%)$ benign adnexal masses and 6 (20\%) malignant adnexal masses. Among 24 benign adnexal masses, there were 7 endometriotic cyst, 4 dermoid cyst, 4 fibroma, 4 mucinous adenoma, 3 haemorragic cyst, one serous adenoma and one ovarian abscess sequelae. While among the 6 malignant masses, there were two serous borderline tumors, two serous carcinoma, one endometrioid carcinoma, and one metastatic tumor.

The prevalence of malignant cases in our sample was similar to Geomini et al. ${ }^{(15)}$ where there were $80 \%$ benign adnexal masses and $20 \%$ malignant adnexal masses. Among the 26 malignant masses, there were 16 serous adenocarcinomas, two mucinous adenocarcinomas, two endometrioid carcinomas, three clear cell carcinomas, two undifferentiated adenocarcinomas of the ovary, and one coeloma carcinoma.

Pervalence of malignancy in our sample was relatively lower than Czekierdowski et $\boldsymbol{a l}^{(\mathbf{1 6})}$ that revealed $25.3 \%$ of tumors were proved to be malignant, and $74.7 \%$ were proved to be benign. Dotlic et al. ${ }^{(17)}$ showed that there were significantly more benign (63\%) than malignant (37\%) tumors.

As regard to age of participating women, women with benign cases was younger than those with malignant cases representing $44.50 \pm 7.62$ vs $46.00 \pm 9.76$ years respectively which is similar to several studies done by Radhamani and Akhila ${ }^{(18)}$ they reported that, patients with malignant HP findings were significantly older than those with benign adnexal masses.

BMI in benign cases ranged from 26.5036.50 with mean value $30.13 \pm 3.21$ lower than recorded in malignant cases (37.70-39.80 with mean value $38.57 \pm 0.81$ ) with statistical significant difference between two studied groups $(\mathrm{P}<0.01)$. Similar to our findings, Dotlic et al. ${ }^{(17)}$ concluded that BMI values were highly significantly higher in the patients with malignant adnexal tumors $(\mathrm{p}=$ 0.001). Also Terzic et al. ${ }^{\left({ }^{(19)}\right.}$ revealed significant differences among tumor types regarding the women's BMI $(\mathrm{P}=0.000)$. Women who had benignant tumors had the lowest BMI. The majority of women with malignant tumors were overweight (BMI: 25-29.99), while most women with benignant tumors had normal weight (BMI: 1824.99) $(\mathrm{P}=0.000)$.

The results of our study correspond with the literature data, that there is a statistically highly significant correlation between higher values of BMI and malignant HP findings of adnexal masses (20)

Regarding to menopausal status, 21 (70\%) women were premenopausal and $9(30 \%)$ were postmenopausal. Benign masses were higher in premenopausal $19(79.2 \%)$ while malignant cases were higher in postmenopausal $4(67 \%)$. Five cases $(83 \%)$ of malignant cases were nulliparous. There was no statistical significant difference between two studied groups regarding maternal history and parity (P > 0.05). Radhamani and Akhila ${ }^{(18)}$ study has similar results, but was not statistically different, whereas other studies have reported more association with malignant disease. Alcázar et al. ${ }^{(21)}$ found that $67 \%$ of women were premenopausal, and $33 \%$ were post-menopausal, while Utrilia-Layna et al. ${ }^{(5)}$ found that $64.6 \%$ were premenopausal and $35.4 \%$ were postmenopausal. Dotlic et al. ${ }^{(17)}$ and Terzic et al. ${ }^{(19)}$ revealed that malignant were more frequent in postmenopausal women $(\mathrm{P}<0.05)$.

The higher percentage of malignant ovarian tumors in postmenopausal women in the present study confrms the characteristic of malignant ovarian tumors being more common in postmenopausal women. on the other hand, patients in the reproductive period more often have benign lesions.

Contrary to what might be expected, in the examined population, the number of pregnancies did not show a significantly different distribution between benign and malignant adnexal masses. Therefore, pregnancy cannot be considered a clear predictive factor that could help in preoperative evaluation of adnexal masses ${ }^{(\mathbf{1 7})}$.

From a clinical point of view of studied cases: most patients presented with lower abdominal pain (12; 40\%), abdominal distention (5; 17\%), multiple symtoms $(5 ; 17 \%)$, asymptomatic $(4 ; 13 \%)$ and menstrual disorders $(4 ; 13 \%)$. In agree with our results, women in Terzic et al. ${ }^{(19)}$ study were either 
asymptomatic or suffered from pain, abdominal swelling, bleeding, urinary disturbances, etc. There were no significant differences among tumor types regarding the symptoms that examined women suffered from $(\mathrm{P}=0.082)$. In Utrilla-Layna $\boldsymbol{e t}$ al. ${ }^{(\mathbf{5})}$ study, most patients $(50.7 \%)$ were asymptomatic, $27.8 \%$ complained of abdominal symptoms (abdominal discomfort, swelling, bloating, constipation, diarrhea or increase in abdominal size), $5.4 \%$ complained of pelvic or lower back abdominal pain and $1.1 \%$ complained of menstrual disorders.

As regard to laboratory findings, there was statistical significant difference between two studied groups regarding WBC $(\mathrm{P}<0.05)$ while, there was no statistical significant difference regarding $\mathrm{RBCs}, \mathrm{Hb}, \mathrm{HTC}$ and prothrombin time (P $>0.05)$. Although contrary to usual findings ${ }^{(22)}$ and our expectations, no other investigated parameter (blood analyses, sedimentation, biochemical analyses) in our population had a statistical significance as a risk factor that could imply to the malignant nature of the tumor, so, in a preoperative tumor evaluation and in the process of deciding on the radicalism of the procedure, they cannot be considered reliable.

Results regarding the diagnostic accuracy for the prediction of adnexal malignancy with 3DPD histogram analysis have been satisfied. Rrsistance index (RI) in benign cases ranged from 0.50-1.90 with mean value $1.18 \pm 0.41$ and in malignant cases ranged from 0.30-1.50 with mean value $0.77 \pm 0.50$. Sensitivity, specificity, PPV, NPV of RI was $78.8 \%, 75.0 \%, 77.2 \%$ and $76.1 \%$ respectively

Pulsatility index (PI) in benign cases ranged from 0.61-2.50 with mean value $1.80 \pm 0.52$ and in malignant cases ranged from 0.80-1.37 with mean value $1.09 \pm 0.24$. Sensitivity, specificity, PPV, NPV of PI was $90.9 \%, 88.0 \%, 91.0 \%$ and $86.5 \%$ respectively

Peak systolic velocity (PSV) in benign cases ranged from 2.00-11.00 with mean value $6.88 \pm 2.71$ and in malignant cases ranged from 14.00-35.00 with mean value 22.83 \pm 7.31 . Sensitivity, specificity, PPV, NPV of PSV was $100 \%, 100 \%$, $100 \%$ and $100 \%$ respectively.

There was statistical significant difference between two studied groups regarding to resistance index, pulsatility index and peak systolic velocity $(\mathrm{P}<0.05)$.

Czekierdowski et al. ${ }^{(16)}$ revealed statistically significant differences between benign and malignant tumors were found for PI (1.06 vs 0.76; $\mathrm{p}$ $=0.001)$, RI (0.62 vs 0.51; p = 0.002), VI (o.55 vs $1.52 ; \mathrm{p}=0.002)$, VFI $(0.18$ vs $0.49 ; \mathrm{p}=0.001)$. However, the highest sensitivity of 3D indices for malignant tumor detection was found for FI $(42.9 \%)$. Specificity of $2 \mathrm{D}$ and 3D indices was between $93.6 \%$ for VI to $98.2 \%$ for RI. Accuracy and positive and negative predictive values were fund to be between $66.8 \%$ to $79.8 \%$ respectively. AUROC's analysis indicated that the most useful test for the discrimination between benign and malignant tumors was VI followed by VFI and PI with RI.

In the previous studies, some authors suggested the existence of clear cut-off values for RI and PI of benign and malignant tumours; Timor Tritsch $\boldsymbol{e t}$ al. ${ }^{\text {(23) }}$ reported the RI value of 0.4 had sensitivity $93.8 \%$ and specifcity of $98.7 \%$. Alcázar and Jurado ${ }^{(7)}$ preferred 0.45. Laban et al. ${ }^{(24)}$ also reported that the best RI cut-off value was $<0.48$ giving a sensitivity, specifcity, and accuracy of $90 \%, 89 \%$, and $90 \%$. Medeiros et al. ${ }^{(25)}$ in their systematic review showed that Doppler can detect malignant masses when the RI was $<0.50$. Ueland et al. ${ }^{(26)}$ reported sensitivity and specifcity of $52.8 \%$ and $77.6 \%$ respectively using cutoff value of PI < 1 . In spite that we found that low PI $<1$ was an important feature of malignancy $(80.4 \%)$ but PI < 1 was also found in $15.7 \%$ of benign masses. So PI alone cannot be a reliable feature to detect malignancy.

In Alcázar et al. ${ }^{(27)}$, 99 non-consecutive women diagnosed as having an adnexal mass were assessed by transvaginal power Doppler ultrasound. 41 masses were malignant and 58 were benign. Agreement between realtime ultrasound and 3D volume analysis was good for both off-line examiners. Sensitivities for realtime ultrasoundand 3D volume analyses were $100 \%$, $93 \%$ and $90 \%$, respectively ( $p>0.05$ ). Specificities for real-time ultrasound and 3D volume analyses were $91 \%, 84 \%$ and $86 \%$, respectively $(\mathrm{p}>0.05)$.

Fagotti et al. ${ }^{(28)}$ evaluated 51 premenopausal women with unilocular-solid adnexal cysts to determine the diagnostic performance of different ultrasound parameters for discriminating benign from malignant lesions. They found that color Doppler, provided a $100 \%$ sensitivity and $80 \%$ specifcity for distinguishing benign and BOT lesions from invasive carcinoma.

Abbas et al. ${ }^{(29)}$ As regards to Doppler indices in the present study, RI and PI values were calculated for each mass. The mean value of RI was 0.79 for benign masses and 0.50 for malignant masses, while the mean value of PI was 1.66 for benign masses and 0.82 for malignant masses. These values, in correlation to various studies using " 0.42 " and " 1 " values for RI and PI respectively as a cutoff value for prediction of malignancy reflected that, RI had a sensitivity of $44 \%$ and a specifcity of 99\%, while PI had a sensitivity of $80 \%$ and a specifcity of $84 \%$. P-value was $<0.001$ for both RI and PI among both groups being of significant value in predicting malignancy of adnexal masses. 
Radhamani and Akhila ${ }^{(18)}$ concluded that, sonography (transvaginal and transabdominal) is a sensitive method for detecting ovarian cancer. Their study showed that abdominal sonography had a sensitivity of $87.5 \%$ and a specifcity of $95.65 \%$ with an accuracy of $95 \%$ for predicting ovarian cancer which is similar to a study by Pourissa et al. ${ }^{(30)}$.

In some studies, the sensitivity of power Doppler diagnostics for prediction of malignancy was up to $75 \%{ }^{\left({ }^{(19)}\right.}$. However, Ohel et al. ${ }^{(31)}$ reported that no significant differences were noted between benign and malignant ovarian tumors for all three indices of vascularity and perfusion on 3DPD ultrasound.

In current study, high risk was higher in malignant cases with $5(83.3 \%)$ and lower in benign cases it is $(1 ; 4.2 \%)$. There was statistical significant difference between two studied groups regarding to $3 \mathrm{D}$ ultrsound examination $(\mathrm{P}<0.05)$.

In agree with our results, Utrilia-Layna et al. (5) studied 223 women, $60.8 \%$ masses were considered as being at low risk for malignancy, $8.2 \%$ as being at high risk for malignancy and $31.1 \%$ as being at intermediate risk for malignancy. Among the 223 considered as low risk, final histology was benign in 221 cases and malignant in two cases. On definitive histological analysis, all 3o cases considered as high risk were malignant and among the 114 cases considered as intermediate risk, 60 were benign tumors and 54 were malignant lesions.

Our results also were in agree with previous a previous study by Huchon et al. ${ }^{(32)}$. They found that cases with a very high risk of malignancy have higher risk scores of 3D-PDA.

\section{Conclusion:}

- 3D ultrasound with color Doppler scan characteristics are found to be very important for discriminating benign from malignant tumors.

- 3D PD imaging has diagnostic potential for the discrimination of benign and malignant complex adnexal masses, but specific, possibly most vascularised areas of each tumor have to be examined in detail to improve this method.

- Ultrasonography has the possible advantage of earlier detection and, therefore, improved survival and avoidance of unnecessary surgery.

- The risk of malignancy is decreased among younger and premenopausal women, who had a prolonged breast-feeding. Symptoms that are associated with ovarian cancer are typically nonspecific. High BMI can be a risk factor for malignancy.

\section{References}

1. Pavlik EJ, Ueland FR, Miller RW, Ubellacker JM, DeSimone CP, Elder J et al. (2013): Frequency and disposition of ovarian abnormalities followed with serial transvaginal ultrasonography. Obstet Gynecol., 122(2 Pt 1):210-7.

2. Givens V, Mitchell G, Harraway-Smith C, Reddy A, Maness DL (2009): Diagnosis and management of adnexal masses. Am Fam Physician, 80(8):815-820.

3. American Cancer Society (2016): Cancer Facts \& Figures. https://cancer.org/.../cancerfacts...cancer-facts-figures/cancer-facts-figures2016.html

4. Kline RC, and Bazzett-Matabele LB (2010): Adnexal Masses and malignancies of Importance to the Colorectal Surgeon. Clin Colon Rectal Surg., 23(2): 63-71.

5. Utrilia-Layna J, Alcazar JL. Auba M. Laparte C et al. (2015): Performance of threedimensional power Doppler angiography as third-step assessment in differential diagnosis of adnexal masses Ultrasound Obstet Gynecol., 45: 613-617.

6. Alessandrino F, Dellafiore C, Eshja E et al. (2013): Differential Diagnosis for Female Pelvic Masses. https://www.glowm.com/.../BookChDifferential\%20Diagnosis\%20for\%20Female $\% 20$

7. Alcázar JL and M Jurado M (2011): Threedimensional ultrasound for assessing women with gynecological cancer: a systematic review Gynecol. Oncol., 120 (3): 340-346.

8. Wu MH, Cheng YC, Chiung-Hsin Chang, Huei-Chen Ko, Chang K (2012):. Threedimensional Ultrasound in Evaluation of the Ovary. Journal of Medical Ultrasound , 136:e141.

9. El-Sharkawy M, El-Mazny A, Ramadan W et al. (2016): Three-dimensional ultrasonography and power Doppler for discrimination between benign and malignant endometrium in premenopausal women with abnormal uterine bleeding. BMC Womens Health, 16: 18.

10. Al-Shukri M, Mathew M, Al-Ghafri W, AlKalbani M, Al-Kharusi $L$ and $V$, Gowri A (2014): Clinicopathological Study of Women with Adnexal Masses Presenting with Acute Symptoms. Ann Med Health Sci Res., 4(2): 286-288.

11. Ormsby EL, Pavlik EJ, Van Nagell JR (2015): Ultrasound follow up of an adnexal 
mass has the potential to save lives. Am $\mathbf{J}$ Obstet Gynecol., 213:657-661.

12. Sayasneh A, Wynants $\mathrm{L}$, Preisler $\mathrm{J}$ et al. (2013): Multicentre external validation of IOTA prediction models and RMI by operators with varied training. Br J Cancer, 108:2448-2454.

13. Alcazar JL, Errasti T, Minguez JA, Galan MJ, Garcia-Manero M, Ceamanos C (2011): Sonographic features of ovarian cystadenofibromas: spectrum of findings. J Ultrasound Med., 20:915-919.

14. Silvestre $L$, Wellington $P$, Martins $Y$ and Francisco J (2015): Candido-dos-Reis. Limitations of three-dimensional power Doppler angiography in preoperative evaluation of ovarian tumors Journal of Ovarian Research, 8:47

15. Geomini KB, Kluivers E, Moret GL, Bremer RF, Kruitwagen BW (2006): Evaluation of adnexal masses with three-dimensional ultrasonography Obstet. Gynecol., 108 (5): 1167-1175.

16. Czekierdowski A, Stachowicz N, Smoleń A, Kotarski J (2006): The use of 2-dimensional and 3-dimensional color and power-Doppler in the diagnosis of blood flow indices of adnexal tumors. Ginekol Pol., 77(4):296-306.

17. Dotlic J, Terzic M, Likic I, Atanackovic J, Ladjevic N (2011): Evaluation of adnexal masses: Correlation between clinical, ultrasound and histopathological fndings. Vojnosanit Pregl., 68:861-6.

18. Radhamani S and Akhila MV (2017): Evaluation of Adnexal Masses - Correlation of Clinical, Sonological and Histopathological Findings in Adnexal Masses. Int J Sci Stud., 4(11):88-92.

19. Terzic MM, Dotlic J, Likic I, Ladjevic N, Brndusic N, Arsenovic N et al. (2013): Current diagnostic approach to patients with adnexal masses: Which tools are relevant in routine praxis? Chin J Cancer Res., 25:55-62.

20. Leitzmann MF, Koebnick C, Danforth KN, Brinton LA, Moore SC, Hollenbeck AR et al. (2009): Body mass index and risk of ovarian cancer. Cancer, 115(4): 812-22.

21. Alcázar JL, García-Manero $M$, Galvan $\mathbf{R}$ (2007): Three-dimensional sonographic morphologic assessment of adnexal masses A reproducibility study. American Institute of Ultrasound in Medicine - J Ultrasound Med., 26:1007-1011.

22. Leelahakorn S, Tangjitgamol S, Manusirivithaya S, Thongsuksai $P$, Jaroenchainon P, Jivangkul C (2005): Comparison of ultrasound score, CA125, menopausal status, and risk of malignancy index in differentiating between benign and borderline or malignant ovarian tumors. J Med Assoc Thai., 88(2): S22-30.

23. Timor-Tritsch IE, Lerner JP, Monteagudo A, Murphy KE, Heller DS. (1993): Transvaginal sonographic markers of tubal inflammatory disease. Ultrasound Obstet Gynecol., 12:56-66.

24. Laban M, Metawee H, Elyan A et al. (2007): Three-dimensional ultrasound and threedimensional power Doppler in the assessment of ovarian tumors. Int J Gynecol Obstet., 99:201-5.

25. Medeiros LR, Rosa DD, da Rosa MI et al. (2009): Accuracy of ultrasonography with color Doppler in ovarian tumor: a systematic quantitative review. Int $\mathbf{J}$ Gynecol Cancer, 19:1214-20.

26. Ueland FR, DePriest PD, Pavlik EJ (2003): Preoperative differentiation of malignant from benign ovarian tumors: the efficacy of morphology indexing and Doppler flow sonography. Gynecol Oncol., 91:46-50.

27. Alcázar JL, Aubá, B (2012): Olartecoechea Three-dimensional ultrasound in gyne-cological clinical practice Med. Imag., 5: 1-13.

28. Fagotti A, Ludovisi M, De Blasis I et al. (2012): The sonographic prediction of invasive carcinoma in unilocular-solid ovarian cysts in premenopausal patients: a pilot study. Hum Reprod., 27(9):26762683.

29. Abbas AM, Zahran KM, Nasr A, Kamel HS (2014): Three-dimensional power Doppler evaluation of adnexal masses. Which parameter performs best? Thai J. Obstet. Gynecol., 22: 102-107.

30. Pourissa M, Refahi S, Moghangard F (2007): The diagnostic accuracy of abdominal ultrasound imaging for detection of ovarian masses. Iran $\mathbf{J}$ Radiol., 4:103-7.

31. Ohel, E. Sheiner, B. Aricha-Tamir, B. Piura, T (2010): Silberstein et al. Three dimensional power Doppler ultrasound in ovarian cancer and its correlation with histology Arch. Gynecol. Obstet., 281: 919-925.

32. Huchon C, Metzger U, Bats AS, Bensaid C, Chatellier G, Azizi M (2012): Value of threedimensional contrast-enhanced ' power Doppler ultrasound for characterizing adnexal masses. J Obstet Gynaecol Res., 38: 832-840. 